\title{
“NÃO MORRERAM DE AMOR, MORRERAM DE PROMISCUIDADE, MORRERAM POR DESCUIDO MESMO”: DISCURSOS DE PROFESSORAS SOBRE TENDENCIOSIDADES E VULNERABILIDADES AO HIV/AIDS MEDIADOS POR ARTEFATOS CULTURAIS
}

\author{
"THEY DID NOT DIE OF LOVE, THEY DIED OF PROMISCUITY, THEY EVEN DIED BY \\ CARELESSNESS": TEACHERS'S DISCOURSES ABOUT TENDENCIES AND \\ VULNERABILITIES TO HIV/AIDS MEDIATED BY CULTURAL ARTIFACTS
}

\author{
Laís Machado de Souza ${ }^{1}$ \\ Marcos Lopes de Souza ${ }^{2}$
}

\section{RESUMO}

Trago nesse artigo uma análise dos principais discursos sobre tendenciosidades e vulnerabilidade são vírus HIV e a Aids construídos por três professoras do componente curricular Educação para a Sexualidade de uma escola dos anos finais de um município no interior baiano. A construção desses discursos se deu durante um encontro formativo realizado com as professoras na escola mediado por artefatos culturais. O encontro fazia parte de uma proposta formativa na área de sexualidade e saúde que foi pensada a partir de uma perspectiva pós estruturalista e inspirada no saber da experiência de Jorge Larrosa. Chamo atenção nesse estudo para algumas percepções, incômodos e estigmas manifestados diante do tema, especialmente, sobre a suposta banalização do HIV/Aids, a aversão às relações ditas promíscuas e o suposto tendenciamento dos artefatos culturais e sua relação com o aumento da vulnerabilidade dos/as jovens.

Palavras-chave: artefatos culturais, educação para sexualidade, vulnerabilidades, HIV/Aids

\section{ABSTRACT}

I bring in this article an analysis of the main discourses on tendentious nessand vulnerabilities regarding the $H I V$ virus and AIDS, constructed by three teachers from the component Education for Sexuality in the final grades of a school of a municipality in the interior of Bahia. The construction of these discourses took place during a formative meeting held with the teachers in the school, mediated by cultural artifacts. The meeting was part of a formative proposal in the area of sexuality and health that was inspired from a poststructuralist

\footnotetext{
${ }^{1}$ Mestra em Educação Científica e Formação de Professores de Ciências e Matemática e Especialista em Saúde Coletiva pela Universidade Estadual do Sudoeste da Bahia (UESB); Bacharela em Enfermagem pela Faculdade de Tecnologia e Ciências (FTC) e licenciada em Ciências Biológicas pela UESB. E-mail: laimachado18@hotmail.com.

${ }^{2}$ Possui Licenciatura e Bacharelado em Ciências Biológicas pela Universidade de São Paulo - FFCLRP (19951998). É mestre (1999-2002) e doutor (2002-2007) em Educação pelo PPGE da Universidade Federal de São Carlos. Realizou pós-doutorado pela Universidade Federal de Juiz de Fora (2014-2015). É professor titular do Departamento de Ciências Biológicas (DCB) da Universidade Estadual do Sudoeste da Bahia, campus de JequiéBA. E-mail: markuslopessouza@gmail.com.
} 
perspective and inspired by the knowledge of Jorge Larrosa's experience. I call attention to some of the perceptions, discomforts and stigmas expressed on the subject, especially on the supposed trivialization of HIV/AIDS, the aversion to so-called promiscuous relationships, and the supposed tendentiousness of the cultural artifacts and their relationship with the increasing vulnerability of young people.

Keywords: cultural artifacts, sexuality education, vulnerabilities, HIV/AIDS

\section{PALAVRAS INICIAIS}

O estigma em relação ao HIV/Aids por ocasião de seu aparecimento no início da década de 1980 colocou a síndrome como resultante de um efeito direto da revolução sexual propagada anos antes, ou seja, uma resposta à "falta de moralidade" da geração de 1968. Em suma, predominava sobre o sujeito "aidético", o estigma de culpabilizado diante de sua própria situação (PELÚCIO; MISKOLCI, 2009; WEEKS, 2000). Assim, diversos estudos e intervenções de caráter preventivo, higienista e epidemiológico começaram a ser realizados de acordo com o modo essencialista de pensar a sexualidade, ou seja, focalizando as práticas e comportamentos sexuais em busca de sua normatização e controle (CORRÊA, 1994; PARKER, 1994; PELÚCIO; MISKOLCI, 2009).

É a partir daí que surgem os conceitos de riscos associados, principalmente, ao homoerotismo que passa a ser então considerado, do ponto de vista epidemiológico, como uma grande ameaça e o do "bom sexo" que seria um reforço à norma heterossexual moralmente aceita, pela qual, teoricamente, se estaria protegido/a do acometimento pelo HIVAids. Sobre os então, epidemiologicamente, denominados como "grupos de risco" foi que o Estado começou a implementar medidas de controle e prevenção da Aids. Entendia-se que os/as indivíduos/as pertencentes a esses tais grupos compartilhavam características, interesses e práticas que os/as enquadravam como potenciais fontes de contaminação.

Nesse sentido, Pelúcio e Miskolci (2009, p. 131) evidenciam que "a compreensão da forma contemporânea de ordenar, classificar e controlar a sexualidade exige retomar o modo como as autoridades de saúde pública reagiram à emergência da epidemia de Aids". De acordo com a autora e o autor, embora a transmissão via transfusão sanguínea do vírus tivesse sido apontada desde a descoberta da doença, o cunho de doença sexualmente transmissível foi 
reiterado e propagado pelos discursos médicos e cristãos da época causando uma espécie de pânico generalizado em torno do sexo, especialmente, em torno das práticas homossexuais e promíscuas. Assim, concluem que analisando os discursos históricos sobre a Aids é possível refletir, inclusive, sobre o processo de "constituição das sexualidades vigiadas" (PELÚCIO; MISKOLCI, 2009, p. 132) que surge justamente a partir do controle dos indivíduos e populações iniciadas no século XVIII.

Não é apenas a homossexualidade e a promiscuidade que ainda incomodam atualmente. É o empoderamento feminino, as discussões dos papéis de gênero, as vivências dos prazeres de forma geral, dentre outros. Heranças de um sistema de controle que não se perdeu durante os séculos, mas se apoderou de novas técnicas. Noções que remetem a existência do momento certo para engravidar e de preferência no contexto do matrimônio ou mesmo a proibição de que seus/suas filhos/as tenham acesso às informações sobre sexualidade consideradas tendenciosas (mesmo as preventivas) em virtude de uma suposta ingenuidade advinda de um doutrinamento cristão são exemplos que nos remetem a tal dispositivo que continua inviabilizando a construção de novas estratégias educativas em sexualidade na escola.

Nesse sentido, essa pesquisa se justifica pela necessidade de conhecer os discursos sobre IST's/Aids produzidos por professoras que atuam diretamente com essas e outras temáticas no contexto de sexualidade e saúde a fim de promover discussões mais aprofundadas sobre o trabalho com a educação para a sexualidade atual e sua articulação com a saúde no ambiente escolar pensando num processo educativo menos essencialista e estigmatizador. Para tanto, foi proposto como objetivo dessa pesquisa: analisar os discursos sobre HIV/Aids produzidos por professoras de uma escola dos anos finais do ensino fundamental da zona urbana de Jequié-BA, durante momento formativo mediado por artefatos culturais.

\section{CAMINHOS INVESTIGATIVOS}

Este estudo é um recorte de uma pesquisa de mestrado concluída, realizada numa perspectiva pós-estruturalista na qual desenvolvi encontros formativos sobre a interface 
sexualidade e saúde com três professoras, as quais me refiro pelos nomes fictícios de Innana, Vênus e Afrodite. Elas ministram o componente curricular Educação para a Sexualidade em uma escola dos anos finais do ensino fundamental da rede urbana, localizada no município de Jequié-BA.

A disciplina de Educação para a Sexualidade é fruto da iniciativa do município que, respaldado na LDB 9.394/96 em seu artigo 11, possui autonomia pedagógica para tanto. Sobre a implantação dessa disciplina no município de Jequié/Bahia, o levantamento realizado por Azevedo (2013) por meio do Conselho Municipal de Educação mostra que ela está inclusa na matriz curricular desde 2005, sendo ministrada no $8^{\circ}$ e $9^{\circ}$ anos do Ensino Fundamental e Educação de Jovens e Adultos (EJA). "Cabe a essa disciplina a abordagem sobre os aparelhos reprodutores, métodos contraceptivos, doenças sexualmente transmissíveis etc, embora o trabalho envolvendo sexualidade seja muito mais amplo" (AZEVEDO, 2013, p.16).

Os encontros formativos foram pensados e desenvolvidos tendo como fonte de inspiração, especialmente, Jorge Larrosa e seus escritos sobre a importância da experiência e do saber da experiência para a formação de professores/as. Assim, o saber da experiência foi explorado, a cada encontro, como forma de pensar a educação para a sexualidade de outra maneira partindo da premissa de que "somente o sujeito da experiência está aberto à sua própria transformação" (LARROSA, 2014, p. 28).

A percepção de formação de professores/as nessa perspectiva não constitui uma doutrina que nos imobiliza, ao contrário, gera inquietude que nos motiva a problematizar a educação em todas as suas vertentes partindo de nossas próprias vivências e com elas aprendendo. Apoiados em Paraíso (2012) é isso que buscamos no tipo de pesquisa que assumimos: aquilo que os/as diversos/as autores/as trazem para o nosso campo de estudo e que tem a potencialidade de nos inquietar. E trazer essa abordagem para a educação para a sexualidade também potencializa a curiosidade, tendo em vista que, a própria sexualidade se produz nos acontecimentos históricos e culturais das experiências das pessoas; o que fundamenta a escolha dessa perspectiva como fonte inspiradora desses encontros formativos. 
Busquei utilizar nesses momentos de formação, materiais educativos diversos enquanto artefatos culturais, explorando-os como ferramentas mediadoras centrais na construção dos discursos das professoras. Esses materiais educativos em sexualidade e saúde, provenientes de instâncias representadas pelo Ministério da Saúde, Ministério da Educação, Organizações não Governamentais, dentre outros, são resultados de uma construção sociocultural que produz, reproduz e divulga significados (SILVA; RIBEIRO, 2011) e, por essa razão, são dotados de pedagogia, ou seja, "também ensinam alguma coisa" (SILVA, 2009, p. 139).

Ao entender o material educativo como artefato que produz, reproduz e divulga significados, assumo que ele orienta a forma como seus/suas leitores/as ou expectadores/as pensam e vivem suas sexualidades. Assim, não dá para negar que nele existe pedagogia, que ele ensina algo sobre sexualidade e sua interface com as questões de saúde. Problematizar esse "algo" enquanto uma construção histórica e cultural, portanto, justifica a escolha de trabalhar com esses materiais na perspectiva dos Estudos Culturais.

Esse recorte que faço em minha pesquisa de mestrado é referente aos discursos

produzidos pelas professoras em um desses momentos formativos no qual utilizei dois vídeos: um material de campanha do Ministério da Saúde que foi ao ar no ano de 1988, denominada “João amava Tereza" que resgata o poema "Quadrilha", escrito em 1954 por Carlos Drummond de Andrade, adaptando-o a uma abordagem preventiva ao HIV/Aids. Este artefato traz uma abordagem preventiva pautada na multiplicidade de parceiros e da liberdade sexual vivenciada pelos jovens nesse período enquanto fator de risco.

$\mathrm{Na}$ mesma linha preventiva ao HIV/Aids, o segundo artefato integra uma campanha dirigida à faixa etária jovem que foi lançada no dia 01 de dezembro de 2014, denominada “\#Partiu Teste”, cujo objetivo, de acordo com o Ministério da Saúde, foi prevenir, testar e tratar dando maior visibilidade às questões do viver com HIV/Aids e à importância do teste e do tratamento como prevenção.

As falas produzidas durante o momento formativo foram gravadas em áudio, transcritas e analisadas tendo como pressuposto as reflexões sobre o discurso com base no referencial foucaultiano. Para Foucault, o discurso é fundante, produz as coisas, os sujeitos, 
nos produzem. Dessa forma, a análise que busquei realizar nessa investigação toma o discurso como um elemento que não é transparente e neutro, mas sim, veiculador, produtor e reprodutor de saberes e poderes, em especial, na área de sexualidade (FOUCAULT, 1988; 1996). Segundo Fischer (2001, p. 222), “o convite de Foucault é que, através da investigação dos discursos, nos defrontemos com nossa história ou nosso passado, aceitando pensar de outra forma o agora que nos é tão evidente".

No item a seguir traremos uma breve apresentação dos artefatos culturais utilizados e uma análise dos discursos construídos pelas professoras após assistirem os materiais escolhidos para o diálogo.

\section{DA BANALIZAÇÃO DO HIV/ AIDS À SUPOSTA TENDENCIOSIDADE DAS CAMPANHAS EDUCATIVAS E SUA RELAÇÃO COM O AUMENTO DA VULNERABILIDADE}

\section{\#partiuteste}

Narrador: Na vida teste novas experiências! Teste escolhas, caminhos... você é jovem!

Jovem a: Eu texto a liberdade!

Narrador: Teste se sentir bem com você!

Jovem b: Eu texto Possibilidades!

Narrador: Teste felicidade! Reinvente a vida! Teste se conhecer!

Jovem c: Eu me conheço. Eu fiz o teste de HIV/aids.

Jovem d: Faça o teste! Por você e por todos.

Todos os jovens: \#partiuteste !

Narrador: Para se prevenir contra o HIV, o vírus da aids, use camisinha e faça o teste! Se der positivo, comece já o tratamento! Se conhecendo melhor você vai seguir em frente, testando o melhor da vida.

(Ministério da Saúde. Campanha contra a aids: \#partiuteste. Vídeo oficial, 2014 
O vídeo de campanha contra a aids do Ministério da Saúde, transcrito acima, suscitou alguns discursos em Innana, Afrodite e Vênus, especialmente, em relação à suposta banalidade atual da síndrome, à possível tendenciosidade de algumas estratégias/materiais educativas/os e sua relação com o aumento da vulnerabilidade dos/as jovens.

Para problematizar a dita banalização da doença, que pareceu gerar certa preocupação e incômodo nas professoras participantes dos momentos formativos, trago para discussão elementos importantes dos trabalhos de Richard Parker. Inicialmente, destaco que a ideia do autor em relação à epidemia é de que ela é também uma construção discursiva. Ele entende que "a imagem que temos sobre a epidemia é necessariamente uma visão ideológica" (PARKER, 2015, p. 3) constituída pelos diversos discursos pessoais em torno dela e que é dentro desses discursos que a realidade da epidemia se constrói.

Ao falar sobre isso, Parker questiona as supostas verdades sobre os números da epidemia da Aids que a mídia atual põe em evidência fazendo menção à suposta diminuição dos números de casos. Ele afirma que muito do que se propaga sobre a epidemia da Aids é fictício, pois não se baseia em dados científicos, mas se fundamentam na noção de um "vírus ideológico". Assim, chama a atenção para o perigos de se acreditar nas histórias sobre a Aids mesmo quando essas sejam contadas por cientistas e gestores.

A existência de um/a "vírus/doença ideológico/a", trabalhados aqui na perspectivas não da ideologia, mas das várias estratégias discursivas em torno dele/a, também parece incomodar Innana, Afrodite e Vênus. Para elas, há um discurso generalizado de banalização da Aids causado, em parte, pelas construções discursivas em torno da eficácia do tratamento da doença.

\footnotetext{
Eu vejo assim: hoje como já tem o tratamento, as pessoas estão se cuidando menos. Eu percebo que a prevenção tá ficando em segundo plano. As pessoas estão percebendo que hoje é normal conviver com as pessoas que têm, mas elas não sabem, por exemplo, a sobrecarga que essas pessoas carregam, o tanto de medicamentos que elas têm que tomar, os sintomas no organismo, os efeitos colaterais (Innana, II encontro. Vídeos de campanhas de prevenção ao HIV e à Aids, grifos nossos).
}

De acordo com as professoras, as ideias sobre a Aids mudaram muito nos últimos anos, o que tem contribuído com a vulnerabilidade dos/as estudantes. A doença que antes 
causava pavor pelo medo da morte é, atualmente, vista como mais uma doença crônica, cujo tratamento permite que o/a soropositivo/a tenha uma vida "normal". Vênus, por exemplo, não deixa de reconhecer a importância do tratamento e os benefícios que trouxeram às pessoas que convivem com o vírus, porém, chama a atenção para o perigo das construções discursivas que os/as jovens têm feito em torno disso. $\mathrm{O}$ medo da morte desaparece e conviver com o vírus já não representa uma ameaça considerável; dessa forma, na percepção das professoras, as estratégias preventivas tendem a diminuir.

As professoras chegaram, inclusive, a questionar o vídeo educativo \#partiuteste do Ministério da Saúde enquanto potencializador desses discursos nos/as estudantes. Segundo elas, algumas abordagens relativas à realização do teste sorológico para que se viva melhor pode parecer aoslàs estudantes, ainda imaturoslas para esse tipo de campanha, que a Aids é algo banal bastando fazer o teste e realizar o tratamento que ficará tudo bem. Para elas dá a falsa ideia de uma suposta segurança, pois ainda que seja exposto, "há o teste, há o tratamento. Ficará tudo bem" (Vênus, II encontro. Vídeos de campanhas de prevenção ao HIV e à Aids).

Sobre isso, penso que as estratégias educativas realizadas no passado com o advento da Aids também não seriam efetivas no contexto atual e que as campanhas precisam explorar os avanços conseguidos até aqui e isso inclui a possibilidade de realização do teste sorológico e do tratamento, inclusive, do tratamento como prevenção. Além disso, não pretendo negar que essas conquistas aliadas ao papel dos movimentos sociais e das diversas estratégias educativas na área tenham surtido efeito na redução de casos nos últimos anos, como aponta os números da epidemiologia.

Contudo, de acordo com Parker, o discurso oficial sobre a epidemia atual diverge consideravelmente da realidade vivenciada pelas pessoas que estão "na linha de frente da Aids". Sendo assim, o suposto sucesso na luta contra a epidemia que, muitas vezes, é reproduzida pela mídia pode criar uma visão "dourada" a respeito dela que merece ser problematizada enquanto um possível fator de aumento de vulnerabilidade (PARKER, 2015, p. 3). 
Por outro lado, quando Innana fala: “As pessoas estão percebendo que hoje é normal conviver com as pessoas que têm, mas elas não sabem, por exemplo, a sobrecarga que essas pessoas carregam", associo isso ao estigma que foi construído em torno da Aids desde a época de seu surgimento; e não é difícil entender porque o preconceito ainda ronda as pessoas que convivem com o vírus e suas relações afetivas e sexuais ainda gerem desconfortos e reprovações. Assim, levando em consideração que o HIV não tem uma "história natural", sendo marcado por fatores políticos e econômicos e sociais (GALVÃO, 2000), considero relevante pensar no imaginário que foi construído em torno da figura do, então chamado, "aidético", no início da epidemia.

A responsabilização dos comportamentos considerados de risco na disseminação do HIV constituiu o discurso de que as pessoas que adquiriam o vírus eram vistas como fonte de sua própria infecção. As pessoas eram entendidas como culpadas e, portanto, perigosas, uma vez que, sua exposição ao vírus teria sido de forma proposital, pois, apesar de conhecerem as consequências de sua conduta, se expuseram irracionalmente a ele. Essa ideia de irresponsabilidade diante de sua própria saúde e de irracionalidade gerava no imaginário social a noção de que essas pessoas representariam uma ameaça, além de a si próprias, também às pessoas que não tinham o HIV (GILMAN, 1991; PELÚCIO; MISKOLCI, 2009).

A ideia propagada de culpa e responsabilidade consigo e com o/a outro/a também preocupa e incomoda os/as jovens soropositivos/as. Para alguns/algumas já é o bastante carregar a culpa de sua irresponsabilidade com a própria saúde, então preferem se relacionar afetiva e sexualmente com pessoas também soropositivas para não se sentirem culpados/as por uma eventual nova infecção (SILVA, 2012). Nesse ponto retomo o entendimento de Richard Parker quanto à existência do tal "vírus ideológico". E além de carregar o estigma da homossexualidade, da prostituição e promiscuidade, carrega também o estigma da culpa e do perigo que representam as pessoas que convivem com o HIV.

Discursos como o de Innana não deveriam ter tanta representatividade nos dias atuais tendo em vista as mudanças socioculturais que culminaram na necessidade de substituição da noção de riscos pela perspectiva da vulnerabilidade ao HIV/Aids. Porém, Pelúcio e Miscolci (2009) ponderam que ele continua forte valendo-se da justificativa de que após anos de 
Revista

Debates Insubmissos

campanhas de prevenção não há explicação para a contaminação, sendo esta uma prova de irresponsabilidade. Percebo com isso, que apesar dos esforços empregados em se estabelecer uma nova compreensão a respeito da disseminação do vírus, continuamos a tratá-lo, quase que exclusivamente, sob um viés comportamental que acaba justificando possíveis preconceitos. 


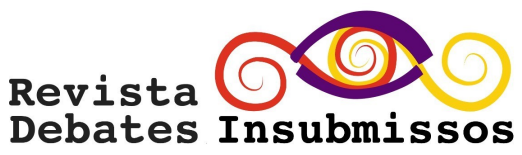

\title{
Quadrilha (adaptado)
}

\author{
João que amava Tereza \\ Que amava Raimundo \\ Que amava Maria \\ Que amava Joaquim \\ Que amava Silvio \\ Que amava Ana \\ Que amava Zeca \\ Que amava Rita \\ Que amava Fábio... que morreu de AIDS! \\ Não Morra de amor! Use camisinha! \\ (Ministério da Saúde. Campanha contra AIDS: Quadrilha (adaptado), 1988).
}

No vídeo de curta duração "João amava Tereza", o narrador declama a primeira parte do poema "Quadrilha", escrito em 1954 por Carlos Drummond de Andrade, de uma forma adaptada enquanto cenas dos/as personagens que se relacionam entre si, de acordo com o poema, vão passando na tela sob um fundo musical que vai ficando cada vez mais pesado até o final do vídeo em que todos os rostos aparecem novamente visivelmente assustados. $\mathrm{O}$ poema tem sua mensagem pautada na multiplicidade de parceiros e da liberdade sexual vivenciada pelos jovens nesse período enquanto fator de risco para a Aids.

A aceitação do artefato por parte de Vênus e Innana foi positiva. Vênus justifica da seguinte maneira porque usaria o vídeo em sala de aula com seus/suas alunos/as:

[...] Ele é interessante porque trata dessas relações da promiscuidade de uma forma leve que é só do amor; fala do amar, do gostar. Então é uma campanha que pode ser vista por adolescentes "numa boa", tranquilamente (Vênus, II encontro. Vídeos de campanha de prevenção ao HIV e à Aids).

Innana também relatou gostar do vídeo e justificou da seguinte forma:

\footnotetext{
Eu acho que o vídeo trata assim que as pessoas antes poderiam desenvolver a doença por uma questão de envolvimento amoroso, por gostar de alguém. Hoje não. Os meninos têm contato com o vírus, na maioria das vezes por meio de um relacionamento casual (Innana, II encontro. Vídeo de campanhas de prevenção ao HIV e à Aids, grifos nossos).
}

Afrodite não compartilha da percepção de Vênus e Innana em relação do artefato de 1988 e põe em discurso suas concepções a respeito de uma cena específica do final do vídeo: 
No final eles falam assim: "Não morra de amor", não é? Só que aí tem uma contradição, porque como é que fulano ama cicrano que ama fulano...? Nessa relação aí a gente tá vendo que um tá se relacionando com o outro sem gostar, quer dizer, o ato sexual ali não está sendo feito por amor porque era um que amava o outro que amava o outro. Está parecendo mais uma promiscuidade! Eu percebi isso. Então, o "não morra de amor" estava se referindo à promiscuidade. Não morreram de amor, morreram de promiscuidade (risos), morreram por descuido mesmo por falta do preservativo (Afrodite- II encontro. Vídeos de campanhas de prevenção ao HIV e à Aids, grifos nossos).

Analisando essas falas e comparando-as com outras que surgiram durante esse encontro formativo, foi possível perceber que Afrodite, Inanna e Vênus possuem a mesma opinião em relação à promiscuidade. $\mathrm{O}$ fato de Vênus e Inanna terem gostado do vídeo de 1988 se deveu mais a uma questão interpretativa do conteúdo de sua mensagem do que a um olhar diferente sobre a multiplicidade de parceiros. Elas apenas consideraram o conteúdo mais leve por trazer em seu contexto a palavra "amor". Penso que se a palavra amor fosse substituída por sexo no poema, apesar do sentido preventivo da mensagem continuar sendo o mesmo, a percepção das duas professoras em relação a ele seria muito parecida com a de Afrodite. Vênus reitera isso ao comentar sobre o vídeo \#Partiuteste em que faz uma crítica à última frase do narrador no vídeo, tecendo relações entre essa e o incentivo da promiscuidade que considera prejudicial aos/as estudantes:

Testando o melhor da vida! Parece que você está se relacionando sempre fazendo teste: se esse aqui não der certo eu pego esse, pego aquela, pego outro, entendeu? Como se relacionamento fosse você estar o tempo inteiromudando de parceiro pra fazer o teste. É como se não tivesse compromisso mesmo. Eu acho que ele dá essa ideia do sexo sem compromisso e alimenta isso nos jovens. Quer dizer que se você se relacionar sexualmente com uma pessoa tem que ser sempre assim? Com essa leveza, sem compromisso nenhum? [...] Para o adolescente, eu acho meio perigoso porque todo mundo pode sair testando. Para o adolescente, eu acho tendenciosa(Vênus - II encontro. Vídeos de campanhas de prevenção ao HIV e à Aids, grifos nossos).

Vênus claramente rejeita as práticas sexuais consideradas promíscuas em ambos os vídeos, embora no vídeo "João que amava Tereza" ela considere aceitável, pois em sua concepção a mensagem passada acaba evocando também o ideal de amor romântico que torna mais "leve" a maneira como a promiscuidade é tratada.

Esse pensamento é reiterado por Vênus e pelas outras professoras também com frequência ao fazerem menção a programas exibidos pela Rede Globo de televisão como 
exemplos de más influências para os/as adolescentes e jovens por incentivar a promiscuidade, como a novela Malhação exibida nos finais da tarde de segunda a sexta e o programa de auditório "Amor e sexo" exibido, na época, no início da madrugada das quintas - feiras. Esses, segundo elas, têm causado danos aos/às jovens por tratarem de conteúdos relativos à sexualidade de uma maneira muito escancarada, dentre eles a promiscuidade sexual.

Os discursos da promiscuidade como uma das causas da transmissão da Aids também esteve presente na pesquisa realizada por Ribeiro ecol. (2005) com profissionais e pacientes acometidos de Aids. Segundo os/as autores/as, na concepção dos/as profissionais, ela apareceu como “[...] doença contagiosa, advinda do sexo promíscuo pelo descuido e o não uso da camisinha". Na época, os/as pesquisadores/as demonstraram que, mesmo após vinte anos da descoberta da síndrome, as representações e discursos em relação à Aids ainda eram muito semelhantes aos do período de seu surgimento. Treze anos após a realização desse esse estudo, percebo que esse discurso em torno da promiscuidade e do descuido também é (re)construído pelas professoras.

Elas reiteram um discurso que põe o que é promíscuo num lugar menor ou menos legítimo que o dos relacionamentos estáveis e isso guarda profundas relações com o estigma que a promiscuidade, historicamente, carrega, especialmente, em relação ao contágio do HIV.

Algumas concepções, nesse sentido, precisam ser questionadas, pois podem incorrer em equívocos baseados no que era tido como verdade há tempos atrás. Innana, por exemplo, traz algumas percepções a respeito da disseminação atual do HIV que não refletem a realidade epidemiológica brasileira. Na fala da professora há o discurso de que os relacionamentos casuais são responsáveis pela maior parte do contágio pelo HIV e que, na época da produção do vídeo (1988), o vírus acometia pessoas mais no contexto de uma relação amorosa entendida como relação estável. A existência de um amor no relacionamento não é garantia de que a pessoa estará isenta de contrair a Aids ou de aquele que não tem amor está fadado a morrer por conta do contágio do HIV, como dito por Afrodite. É interessante colocar esses discursos sob suspeita.

Chamo atenção para as armadilhas que discursos como esse podem representar em termos de aumento da vulnerabilidade no contexto das relações estáveis e, supostamente, 
afetivas. Trago, nesse sentido, elementos do trabalho de Parker e Galvão (1996) para contextualizar como funcionam esses estigmas em relação aos relacionamentos casuais fazendo um contraponto com as relações de gênero.

Os autores discutem que no contexto da associação entre HIV/Aids e promiscuidade, as mulheres consideradas promíscuas têm sido consistentemente responsabilizadas pela elevação dos números da transmissão heterossexual. Entretanto, eles apontam que os dados epidemiológicos no Brasil evidenciam um alto e crescente índice de transmissão heterossexual entre mulheres casadas ou em união estável e que se dizem monogâmicas. Apesar disso, a epidemia heterossexual ainda tem sido associada ao comportamento das mulheres consideradas "fáceis" e que possuem uma variedade de parceiros sexuais. Portanto, afirmar que os relacionamentos casuais são responsáveis, atualmente, pela maioria das infecções pelo HIV é deixar de considerar contextos socioculturais e incorrer no risco de reiterar abordagens preventivas pautadas em grupos e/ou comportamentos de risco.

Quando a professora Afrodite afirma que "Não morreram de amor, morreram de promiscuidade”, reproduzem a antiga ideia de existência de comportamentos de risco. Há elementos nesse discurso que diminuem a responsabilidade daqueles que vivem num contexto de relações monogâmicas e/ou matrimoniais; representações que trazem elementos próprios do século XX por ocasião do aparecimento da Aids. Sobre esses resquícios, Parker e Aggleton (2006) destacam que toda a história da epidemia do HIV e da Aids foi e continua sendo marcada pela estigmatização e discriminação, especialmente, em relação à homossexualidade, à prostituição dentre outros/as e à promiscuidade que funcionam ainda hoje como os aspectos mais enraizados do estigma.

A questão central aqui me parece ser as relações de poder que perpassam o discurso das professoras sobre o comportamento promíscuo. Ao colocá-lo em um lugar ilegítimo e subvalorizado, elas estão automaticamente se colocando em uma posição de valor e legitimidade na condição de mulheres ditas monogâmicas e em uma relação estável. Desse lugar, que lhes parece o mais correto a se estar, sentem-se autorizadas a falar e também (re)produzir para os/as estudantes um saber que inferioriza a promiscuidade colocando, assim, em movimento jogos de poder-saber. 
Assim, reitero que essa associação entre comportamento promíscuo com a Aids e outras infecções sexualmente transmissíveis ou a gravidez na adolescência se configuram como possíveis bases sobre a qual se fundamentam tal aversão à promiscuidade (CARRARA, 2015). Contudo, o que considero importante salientar aqui é a análise que fazem do artefato enquanto produtor de vulnerabilidade para o comportamento promíscuo, inclusive, por se tratarem de vídeos de campanha veiculados na mídia. Uma dessas mídias veicula os programas televisivos criticados pelas professoras como "Malhação" e "Amor e sexo".

Jimena Furlani considera que essa noção de quebra da inocência e de suposto desaparecimento da infância presente nos discursos da sociedade atual tem sido muito relacionada com o que ela chama de "era da televisão" que na concepção social:

[...] expôs o mundo reservado da vida adulta ao olhar infantil e tem permitido a inevitável e "perigosa" aproximação de crianças e adolescentes dos "algozes" da contemporaneidade: a precocidade sexual, o erotismo comportamental, as drogas, a violência, a criminalidade, a promiscuidade, o desafeto familiar, a corrupção moral, a pedofilia entre outros (FURLANI, 2005, p. 172).

Nesse sentido, Furlani ainda compartilha em sua tese de doutoramento uma reportagem da revista Veja de 1996 que mostra o quanto recorrente é a associação da TV como responsável pela erotização infantil considerada precoce. De acordo com a reportagem um acusado pelo estupro de uma garota de 12 anos foi inocentado pelo Supremo Tribunal Federal (STF) tendo como justificativa o seguinte argumento do então relator do processo Ministro Marco Aurélio de Mello:

Nos nossos dias, não há crianças, mas moças de 12 anos. Precocemente amadurecidas a maioria delas já conta com discernimento bastante para reagir ante eventuais adversidades[...] Sendo irrestrito o acesso a mídia não se mostra incomum reparar-se a precocidade com que as crianças de hoje lidam, sem embaraços quaisquer, com assuntos concernentes a sexualidade, tudo de forma espontânea, quase natural (VEJA apud FURLANI, 2005 p.172).

A ideia que associa a criança com a inocência e a pureza ainda persiste nos dias atuais. Segundo essa perspectiva, para que ela cresça e se desenvolva de maneira saudável seria necessário que a sexualidade não fosse "precocemente ensinada" tanto pela mídia quanto em sala de aula no contexto das aulas de educação para a sexualidade (FURLANI, 2005). Parece- 
me uma ideia que também permeia a fala de Vênus sobre o vídeo de campanha; não de uma maneira totalizante, uma vez que, a professora apoia e defende a educação para a sexualidade na escola, contanto que essa se dê forma comedida sem confrontar antigos valores morais e direcionada a uma faixa etária que ela considera mais preparada para lidar com essas temáticas.

Fischer (2002) vai de encontro a essa concepção radical a respeito da mídia, especialmente, a televisão sob a qual se debruça seus estudos. Ela acredita que o sentido da educação escolar se amplia com a contribuição dos meios de comunicação, pois eles podem auxiliar no aprendizado sobre os modos de existência, de comportamento e de constituição de si mesmo para os diversos grupos sociais, especialmente, as populações mais jovens. Esse entendimento da autora apresenta os elementos midiáticos em uma perspectiva educativa e não tendenciosa ou influenciadora, cujas possibilidades podem ser grandes quando e se exploradas.

Sobre vídeo \#partiuteste, Afrodite, apesar de já haver tecido críticas ao comportamento dito promíscuo em relação ao vídeo de 1988, evidenciou algumas características que, segundo ela, favorecem a sua utilização com o público jovem; como tratar do tema HIV/Aids com uma linguagem moderna comum a esse público o que, na sua opinião, favorece o processo educativo. Também não concentrou seu discurso sobre aspectos morais, mas sobre as potencialidades preventivas da maneira como o artefato aborda a realização do teste do HIV. Ao fazer isso, procura defender em sua fala a necessidade de valorizar a utilização do teste diminuindo a rejeição e/ou não adesão, ainda muito comum no país, tomando como exemplo a sua vida pessoal:

Eu usaria por que é um vídeo bastante moderno. O lado positivo é que trata o teste para o HIV como uma coisa natural, que qualquer um pode fazer. Por que não se pode ter medo de fazer o teste. Eu mesmo faço todo ano toda vez que eu faço preventivo. Eu acho uma coisa normal. Não que eu desconfie do meu marido, mas eu faço porque tem que fazer. Isso pra mim é uma coisa natural(Afrodite, II encontro. Vídeos de campanhas de prevenção ao HIV e à Aids, grifos nossos).

A análise que Afrodite fez do artefato evidencia um discurso mais aberto e menos conservador que o de Vênus em relação ao mesmo material. O fato de o artefato trazer uma abordagem preventiva e de diagnóstico precoce do HIV de forma mais direta e moderna, sem 
grandes preocupações com moralidades, mas sim com uma mensagem de incentivo às novas experimentações entre os/as jovens é vista por Afrodite de maneira positiva pela possibilidade de esse ser mais significativo e, portanto, causar um impacto maior entre a população jovem.

Uma questão que me provocou na fala de Afrodite foi justamente algo que apareceu anteriormente na fala de Vênus e que diz respeito ao lugar atribuído ao matrimônio. Vênus questionou em sua fala a existência do sexo seguro, inclusive para ela que era casada dando a entender que a instituição do matrimônio deveria the proporcionar maior segurança em relação às IST/Aids, apesar de não ter garantia disso. Aqui consigo vislumbrar fortes associações entre esse discurso e o de Afrodite.

A professora parece ter a necessidade de justificar que o fato de realizar anualmente o teste de HIV não está relacionado a uma suposta desconfiança em relação ao seu cônjuge, mas trata-se apenas de uma rotina. Nessa fala de Afrodite também há o antigo discurso de moralidade e pureza do matrimônio, como se isso fosse inquestionável e que há a necessidade de a mulher se justificar toda vez que solicitar do companheiro o uso do preservativo ou admitir que realiza ou já realizou o teste para o HIV. O receio de solicitar o uso do preservativo ao companheiro deriva do medo de ser interpretada como infiel e promíscua. São heranças de uma representação, ainda muito difundida, de que se a sua prática sexual for “moralmente respeitável" (afetivo, monogâmico e no contexto de uma relação estável, especialmente, conjugal), menores serão os riscos (PELÚCIO; MISKOLCI, 2009).

Considero relevante pensar essas questões para salientar o quanto elas ainda têm influenciado a tomada de medidas preventivas em relação ao HIV/Aids e, por isso, precisam ser problematizadas não apenas entre os/as estudantes, mas também entre os/as educadores/as.

\section{ALGUMAS CONSIDERAÇÕES}


Esse trabalho demonstrou a problemática atual e o reducionismo cometidoao se abordar as ISTs/Aidssob a perspectiva do conceito de risco, pois mesmo que isso não seja confessado abertamente, o termo ainda guarda desde o século passado, na concepção de Pelúcio e Miskolci (2009) uma associação com a noção de perigo, sujeira e poluição que culpabiliza e acusa aqueles/as que escapam às normas da sexualidade considerada como padrão em nome da vivência dos prazeres de forma livre.

Também percebi nessa pesquisa que, ao mesmo tempo em que a utilização dos artefatos culturais suscitava o discurso em torno do biológico (preventivo); da aversão à promiscuidade e do medo de que os materiais educativos em saúde influenciassem os/as estudantes na tomada de decisões consideradas perigosas em relação à sua vida sexual, também levava as professoras a problematizarem em alguns momentos os seus próprios discursos, como o faz Afrodite ao vislumbrar importantes possibilidades educativas no vídeo \#partiuteste.

Nesse sentido, o trabalho com os artefatos culturais enquanto mediadores na produção de discursos de Innana, Afrodite e Vênus me fez problematizar pré-conceitos e estigmas, mas também vislumbrar novas possibilidades discursivas sobre sexualidade e saúde e sua abordagem em sala de aula no âmbito da educação para a sexualidade que extrapole a perspectiva unicamente preventiva.

\section{REFERÊNCIAS}

AZEVEDO, S. M. M. M. Estudo Investigativo da disciplina Educação para a Sexualidade em escolas da rede municipal de Jequié-BA. 144p. Dissertação (Mestrado em Educação Científica e Formação de Professores) - Universidade Estadual do Sudoeste da Bahia, Jequié, 2013.

CAREGNATO, Rita Catalina Aquino; MUTTI, Regina. Pesquisa qualitativa: análise de discurso versus análise de conteúdo. Texto Contexto Enferm, Florianópolis, v.4, n.15, p.679-684, outdez. 2006. 
CARRARA, Sérgio. Moralidades, racionalidades e políticas sexuais no Brasil contemporâneo. Mana. Rio de Janeiro, v. 21, n. 2, p. 323-345, mar. 2015.

CORREAA, Mariza. Repensando a família patriarcal brasileira. Cadernos de Pesquisa. São Paulo, v. 37, p. 05-16, mai. 1981.

DELEUZE, Gilles. Foucault. São Paulo: Brasiliense, 1991

FISCHER Rosa Maria Bueno. Foucault e a análise do discurso em educação. Cadernos de Pesquisa, n. 114, p. 197-223, nov. 2001.

FISCHER Rosa Maria Bueno. O dispositivo pedagógico da mídia: modos de educar na (e pela) TV. Revista Educação e Pesquisa. v. 28, n. 1, p. 151-162, jan-jun. 2002.

FOUCAULT, Michel. História da sexualidade 1: A vontade de saber. Rio de Janeiro: Graal, 1988 FOUCAULT, Michel. A ordem do discurso. São Paulo, Loyola, 1996

FURLANI, Jimena. O bicho vai pegar! - um olhar pós-estruturalista à educação sexual a partir de livros paradidáticos infantis. 272p. Tese (Doutorado do Programa de pós Graduação em Educação) - Universidade Federal do Rio Grande do Sul, Porto Alegre, 2005.

GALVÃO, Jane. Aidsno Brasil: a agenda de construção de uma epidemia. Rio de Janeiro; ABIA, 2000

GROTZ, Fabio; PARKER, Richard. O retorno do vírus ideológico. Boletim ABIA, n. 60, p. 1921, jun. 2015.

LARROSA, Jorge. Tremores: escritos sobre a experiência. Belo Horizonte: Autêntica, 2014

PARAÍSO, Marlucy Alves. (org.). Metodologias de pesquisas pós-críticas em educação. Educ. foco, Juiz de Fora, v. 18, n. 2, p. 271-279, jul-out. 2013

PARKER, Richard. A construção da solidariedade: Aids, sexualidade e política no Brasil. Rio de Janeiro: Abia, IMS-UERJ, Relume-Dumará, v. 10, n. 3, p. 400-407, Ju1/Set. 1994.

PARKER, Richard. O fim da Aids? Rio de Janeiro: ABIA, 2015. 
PARKER. Richard; GALVÃO. Jane (org.). Quebrando o silêncio. Mulheres e Aids no Brasil. (História Social da Aids, n. 7). ABIA-IMS/UERJ, Relume-Dumará, Rio de Janeiro, 1996

PARKER, Richard; AGGLETON, Peter. Estigma, discriminação e AIDS. Rio de Janeiro: ABIA, 2006

PELÚCIO, Larissa; MISKOLCI, Richard. A prevenção do desvio: o dispositivo da aids e a repatologização das sexualidades dissidentes. Sexualidad, Salud y Sociedad - Revista Latinoamericana,Rio de Janeiro: CLAM-UERJ, n. 1, p.125-157, 2009.

RIBEIRO, Cristiane, G.; CASTANHA, Alessandra R.; COUTINHO, Maria P. L.; SALDANHA, Ana A. W. A Aids e suas contradições: representações sociais de seu atendimento e tratamento pelos profissionais e pacientes. DST - Jornal Brasileiro de Doenças Sexualmente Transmissíveis. v.17, n.2, p.127-132, nov. 2005.

SILVA, Benícia Oliveira da; RIBEIRO, Paula Regina Costa. Sexualidade na sala de aula: tecendo aprendizagens a partir de um artefato pedagógico. Estudos Feministas, Florianópolis, v. 19, n. 2, p. 521-533, mai-ago. 2011.

SILVA, Jeane Féliz. “Quer teclar?”: aprendizagens sobre juventudes e soropositividades através de bates-papos virtuais. 223p. Tese (Doutorado em Educação) - Universidade Federal do Rio Grande do Sul, Porto Alegre, 2012.

SILVA, Tadeu Tomás. Documentos de identidade: uma introdução às teorias do currículo. 3 . ed. Belo Horizonte: Autêntica, 2009

SOUTO, Bernardino Geraldo Alves; KIYOTA, Laurene Sayuri; BATALINE, Mariana Pereira; BORGES, Mariana Ferreira; KORKISCHO, Nádia; CARVALHO, Sabrina Boni Braga de. O sexo e a sexualidade de portadores do vírus da imunodeficiência humana. Rev. Bras. Clin Med. v. 7, n. 1, p. 188-191, 2009.

VEIGA-NETO, Alfredo. Foucault e a Educação. 3 ed. Belo Horizonte: Autêntica, 2016

WEEKS, Jeffrey. O corpo e a sexualidade. In: LOURO, Guacira Lopes. (Org.). O corpo educado: pedagogias da sexualidade. 2 ed. Belo Horizonte: Autêntica, 2000. p. 24-61. 